\title{
REVIEW ON WEB BUCKLING AND HYSTERETIC BEHAVIOR OF SHEAR PANEL DAMPERS
}

\author{
Zhiyi Chen ${ }^{1,2,3}$, Guoqiang Bian ${ }^{3}$ and Yu Huang ${ }^{3,4, *}$ \\ ${ }^{1}$ Associate Professor, Key Laboratory of Geotechnical and Underground Engineering of the Ministry of Education, \\ Tongji University, Shanghai 200092, China \\ ${ }^{2}$ State Key Laboratory of Geo-Hazard Prevention and Geo-Environment Protection, \\ Chengdu University of Technology, Chengdu 610059, China \\ ${ }^{3}$ Department of Geotechnical Engineering, Tongji University, Shanghai 200092, China \\ ${ }^{4}$ Professor, Key Laboratory of Geotechnical and Underground Engineering of the Ministry of Education, \\ Tongji University, Shanghai 200092, China \\ *(Corresponding author: E-mail: yhuang@tongji.edu.cn)
}

Received: 29 December 2011; Revised: 24 March 2012; Accepted: 2 April 2012

\begin{abstract}
Recently shear panel dampers (SPDs) have been applied to building and bridge structures widely, showing good effects in seismic hazard mitigation as passive energy dissipators. The mechanism of SPDs for dissipating earthquake-induced energy is through inelastic shear deformation of the metal. This paper firstly gives a brief introduction to the new development of configuration and material of SPDs. Then two important issues, namely, web buckling and hysteretic behavior of SPDs are mainly addressed. Several structural parameters, which have influences on bearing capacity, ductility and energy dissipation capacity of SPDs, are also discussed, with regarding to web slenderness ratio, stiffness of stiffeners, and contribution of flanges. Additionally, various restoring models of SPDs, which is developed to be used in evaluation of seismic control structures, are also discussed together with their hysteretic behavior. Finally, application of SPDs in building and bridge structures is presented, pointing out the issues deserving further study and potential application to new field of civil engineering.
\end{abstract}

Keywords: Shear panel damper, Energy dissipation device, Passive energy dissipator, Web buckling, Hysteretic behavior

\section{INTRODUCTION}

Over the past 30 years, the research on structural vibration control in building and bridge structures has been developed greatly. Many types of vibration control strategy are established [1,2]. A passive control system is one of them, referring to a class of control systems which do not require an external power source [1]. According to the way dissipating energy (such as adding internal stressing, rubbing, cracking, and stable plastic deformation), passive control devices can be classified into hysteretic dampers, friction dampers, viscoelastic solid dampers, and viscous fluid dampers, as shown in Figure 1.

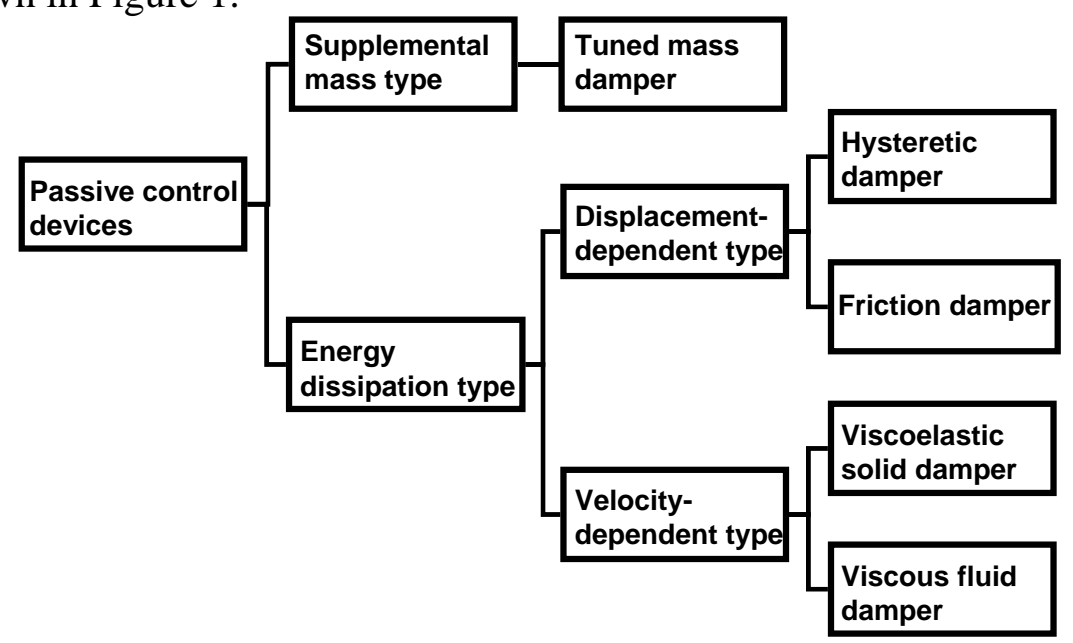

Figure 1. Classification of Passive Control Devices 
A shear panel damper (SPD), as presented in this paper, belongs to the hysteretic damper. For a successful hysteretic damper, it must effectively translate forces developed in response to the structural motion and dissipate as much of the energy input as possible at locations. The SPD has already been applied to many civil structures to control seismic responses and damage of the main members [3-6], due to its advantages of simple configuration, easiness to repair and/or replace. A properly designed shear panel damper may be into plasticity prior to the main structure. Moderate or large shear deformation may develop in the web of an SPD. Then the device absorbs seismic energy introduced into the structure during an earthquake event. Through metal inelastic deformation, SPD devices prevent the main structure from being damaged or destroyed. The working mechanism of an SPD is unlike to other hysteretic dampers, such as ADAS (added damping and stiffness) [7], TADAS (triangular ADAS) [8], Cu-ADAS (copper ADAS) [9], and SSD (steel slit damper) [10], and BRB (buckling restrained braces) [11]. They make use of metal deformation in flexural and axial manner. According to the location of being in main structures, SPDs can be divided into two types: (1) a combined-type that consist of shear panel and braces; (2) an inner column-type, as shown in Figure 2 [12].

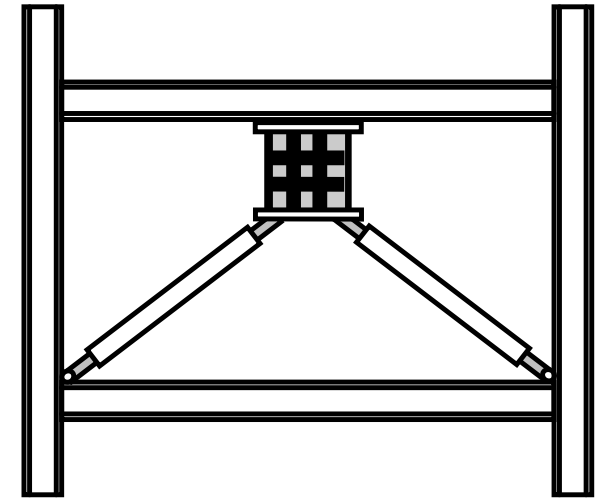

(a) combined type

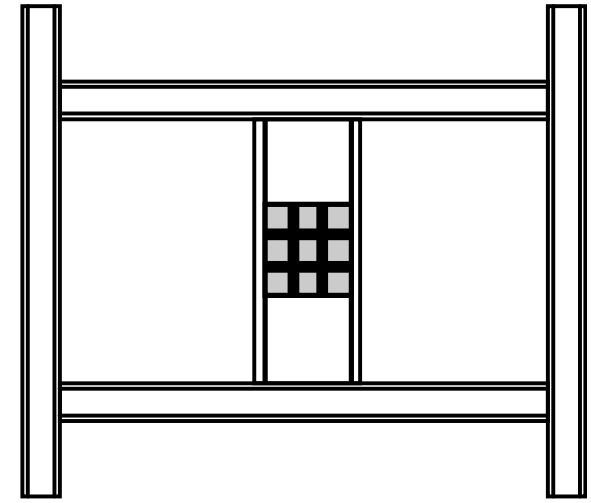

(b) inner column-type

Figure 2. Examples of Shear Panel Dampers Incorporated into Framed Structures

Interest in the development of SPDs has greatly increased in recent years. This leads to a great fruit and have prompt development and use of SPDs in practices. Researchers have pay close attention to SPDs, covering its behavior caused by different metal material and configuration, web buckling and effects of stiffeners, ultimate strength and ductility, as well as hysteretic performance and corresponding restoring models. Of these, two issues, namely web buckling and hysteretic behavior of SPDs are of great concern. Web buckling should be avoided for SPDs during early stages to sustain good hysteretic performance. The hysteretic behavior directly determines energy dissipation capacity of SPDs. In view of this, this paper mainly focuses on the new development of web buckling and hysteretic behavior of SPDs in recent years, points out the main issues which should be considered in practice. The application and suggestions in use of SPDs are also presented at the end of this paper.

\section{CONFIGURATIONS AND MATERIALS}

Configuration and material must firstly be considered for the design of shear panel dampers. They are most important factors and largely determine the web buckling and hysteretic behavior of shear panel dampers. 


\subsection{Configurations}

Indeed, development of shear panel damper is originated from the concept to weaken the beam end so as to mitigate seismic damage to the column and the main part of the beam. The basic configuration of an SPD is somewhat like a connection part of an $\mathrm{H}$ steel beam-column. As shown in Figure 3(a), previously published researches about shear panels focused on unstiffened shear panels $[4,13]$. It is commonly composed of a web which is obviously the main part, acting as a damper, and flanges being welded at the left and right sides of the web. In Figure 3, the rocky steel plates at the top and the bottom of the web are used to fix the SPD to the upper beam or to the bottom braces (see Figure 2(a)). The most advantages of such SPD type is its simple configuration and hence feasibility to manufacture. However due to the large width-thickness ratio of the web, local buckling occurs prior to web yielding. Local buckling is not preferable because it is the main reason to degrade the energy dissipating capacity. Hence the web thickness of the shear panels in the early researches is always designed stocky.

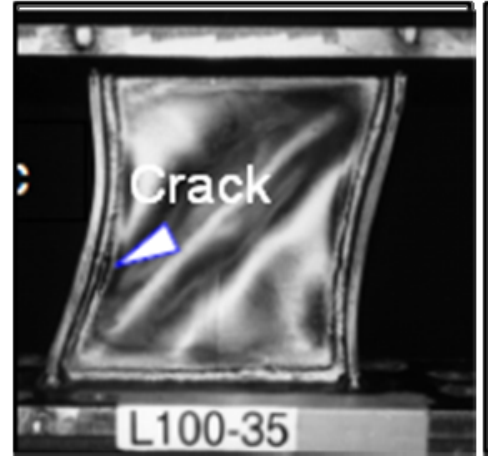

(a) unstiffened [4]

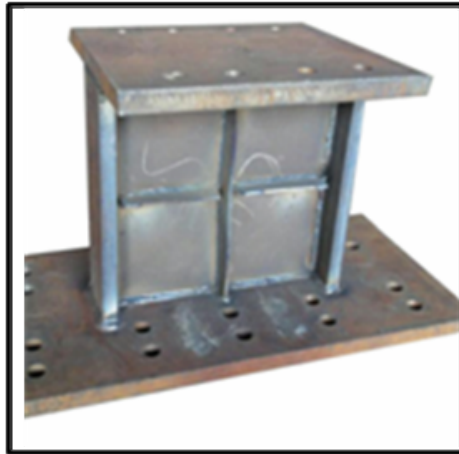

(b) stiffened

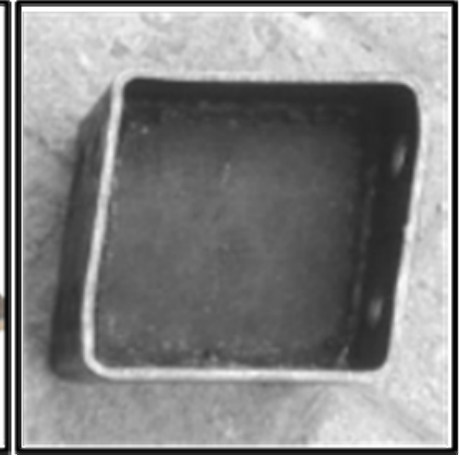

(c) square hollow section type [15]

Figure 3. Various Configurations of SPDs

An alternative way to avoid local buckling is to strengthen the web with stiffeners at one side or both sides. In recent researches [12,14], stiffened shear panel dampers are widely studied, as shown in Figure 3(b). The main purpose of fixing stiffeners is to increase shear buckling strength of the web, being similar to the rib in a girder. With stiffeners, even an SPD of the large width-thickness ratio may possess good hysteretic behavior and energy-dissipation capacity. Another advantage of stiffeners is that it may improve ductility capacity of an SPD remarkably while it may not change the yield strength. As a result, the yield strength can be determined by the cross-section area of an SPD, which simplifies practical design. To a stiffened SPD, however, the fatigue performance at the welds and the centre portion of the web should be verified.

Not only added stiffeners but also enhanced web boundaries may effectively prevent the web from premature local buckling. Chan et al. [15] proposed a so-called yielding shear panel device, in which a thin diaphragm steel plate as a damper is welded inside a square hollow section to improve its anti-buckling performance. The configuration of the device is shown in Figure 3(c).

In addition to the classic configuration, a laminated composite-type [16,17] — fiber orientations and stacking sequence of laminated composite panels are adopted to absorb seismic energy. Laminated composite-type shear panel dampers are usually used in link region between two main building structures. It supplies considerable lateral stiffness by the sandwich type at a high lateral drift level to resist shear displacement [16]. Such a damper is strict on the material demanding, and needs to consider the interaction of interlayer contacts. Aref and Jung [16] designed the passive interface damping layers to enhance damping properties under shear loading. Existing results show that their 
hysteretic performance is not so perfect while their fabrication is relative complex. Such shear panel dampers is easy being damaged, because their physical properties are very different and their boundary problem is a difficult issue which should be solved in the future.

\subsection{Materials}

Compared to structural control devices which are made of viscous liquid, friction of lead materials, uses of hysteretic behavior of metal material is attracted due to its low price, reliability and durability. So far, mild steel, low yield point steel, pure aluminum, aluminum alloy and composite material are often used as the main material to dissipate seismic energy. Their advantages and disadvantages are summarized in Table 1.

Table 1. Advantages and Disadvantages of Metals used as Damper Material

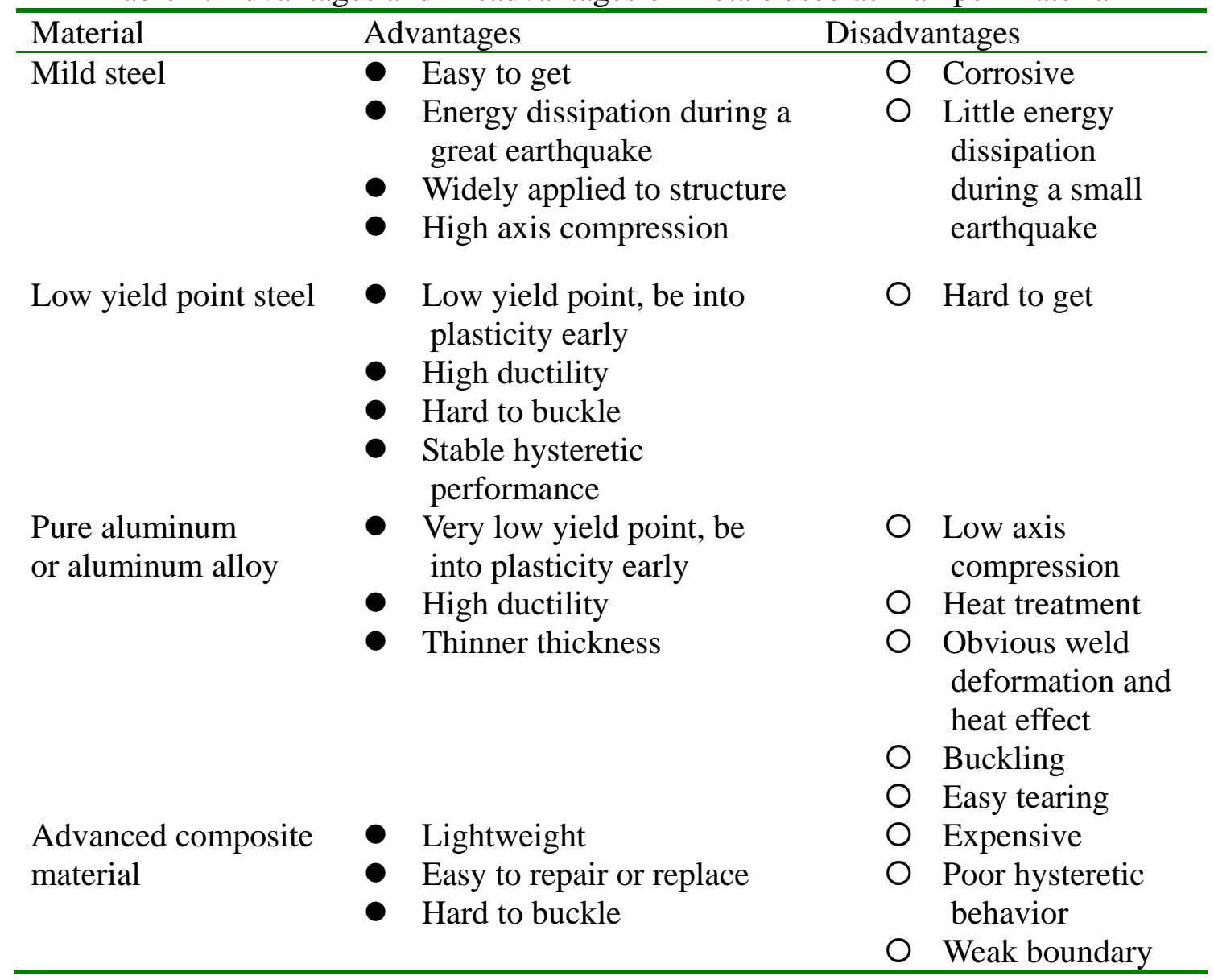

In the early stages of development and research, mild steel is generally used as the energy-dissipating material. Since use of mild steel in structural construction has a long history, its mechanical properties are well known. Shear panel dampers made of mild steel may offer added stiffness to the main structure during a small earthquake, and absorb seismic energy through hysteretic deformation when suffering a great earthquake. It should be noted that such damper fails to work in a small earthquake due to its high strength.

In view of this, low yield point steel is developed lately in Japan. This kind of steel mainly has three levels of yield strength as $100 \mathrm{MPa}$ (or 120MPa), 160MPa, and 225MPa. They have large elongation ranging from 40 to $60 \%$ [3]. Figure 4 shows material test curves of BT-LYP100 and BT-LYP225 provided by Nippon Steel Corporation [18]. In the plot, BT-LYP100 material has a nominal initial yield point of $100 \mathrm{MPa}$, over $50 \%$ rupture strain, and excellent ductility performance 
[18]. Due to the really low yield strength, dampers made of this kind of low yield point steel may yield and take effect even in a small earthquake if compared to those of mild steel. In addition, the manufacturing process of low yield point steel is strictly controlled so that the scatter of the yield strength is very small. The merit of a narrow range of yield strength scatter is that seismic control effect of a metal damper is guaranteed under designed loads. It is because the metal damper is designed to yield prior to the main structure.

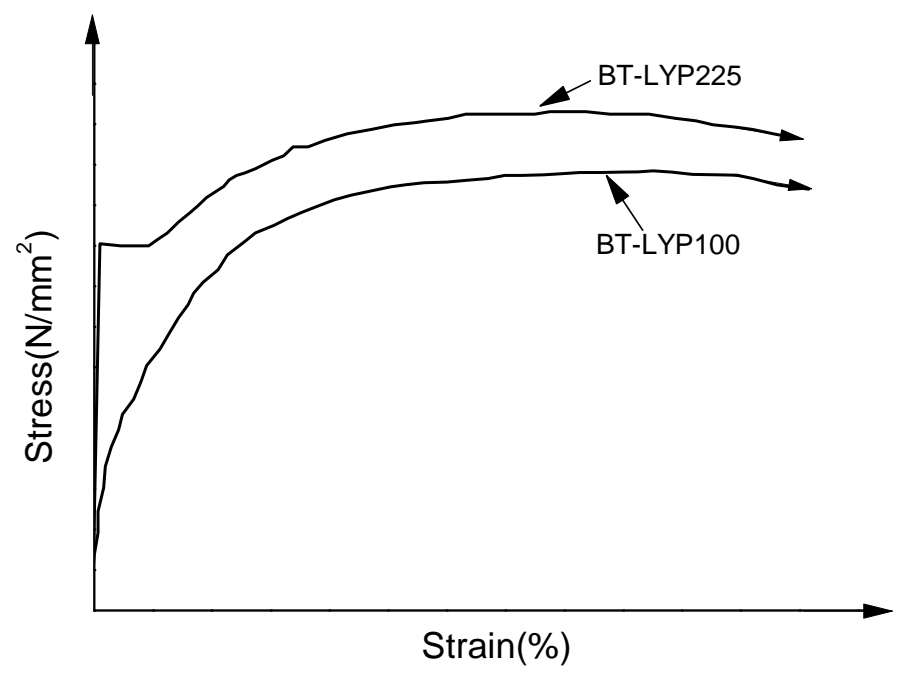

Figure 4. Stress-strain Curve of Low Yield Point Steel [18]

Aluminum is an innovative material recently proposed in the field of seismic engineering, due to its low yield strength and high ductility features $[19,20]$. Table 2 shows the mechanic characteristics of low yield point steel, aluminum and pure aluminum. Rai [21] made use of low yield point aluminum alloy (3003-O). Its yield stress is 35.2MPa after improving its mechanics behavior by heat treatment, and elastic modulus is 62 GPa. De Matteis et al.[19] used AW 1050A alloy, characterized by a high degree of purity (more than 99.50\%), a limited conventional yield strength (about $20 \mathrm{MPa}$ after heat treatment), high hardening ratio (about 4), and high ductility (about 40\%). These features benefit to shear panel dampers. The web can be made very thin while the SPD still has high ductility. However a thin aluminum web tends to remarkable buckling and the web is easily teared. Due to excessive low shear strength of pure aluminum or aluminum alloy, they got into plastic status quickly, and pinching of the hysteretic curve was observed under lateral cyclic load [19].

Table 2. Mechanical Characteristics of Low Yield Point Steel, Aluminum and Pure Aluminum

\begin{tabular}{|c|c|c|c|c|c|}
\hline Material & $\begin{array}{c}0.2 \% \text { offset } \\
\text { yield stress } \\
\left(\mathrm{N} / \mathrm{mm}^{2}\right)\end{array}$ & $\begin{array}{l}\text { Maximum } \\
\text { stress } \\
\left(\mathrm{N} / \mathrm{mm}^{2}\right)\end{array}$ & $\begin{array}{l}\text { Young's } \\
\text { modulus } \\
\left(\mathrm{N} / \mathrm{mm}^{2}\right)\end{array}$ & $\begin{array}{c}\text { Rupture strain } \\
\text { (\%) }\end{array}$ & $\frac{(1)}{(2)}$ \\
\hline & (1) & (2) & (3) & (4) & (5) \\
\hline LYP steel & 86 & 254 & 210000 & 50 & 0.339 \\
\hline $\begin{array}{l}\text { Aluminum alloy } \\
\text { (3003-O) }\end{array}$ & 35.2 & 109.2 & 62000 & -- & 0.322 \\
\hline $\begin{array}{l}\text { Pure aluminum } \\
\text { (AW 1050A) }\end{array}$ & 21.3 & 80 & 70000 & 45 & 0.266 \\
\hline
\end{tabular}


With the development of material science, composite material has been widely used. Composite materials, often shortened to composites, are engineered materials made from two or more constituent materials with significantly different physical or chemical properties which remain separate and distinct on a macroscopic level within the finished structure [22]. The physical properties of composite materials are generally anisotropic, nonhomogeneous, lightweight, easy to cut, thinner thickness and so on. Aref and Jung [16] made use of fiber reinforced polymer matrix composite (PMC) material as the web of an SPD. The PMC material is a semi-rigid PVC foam. It has the superior strength-to-weight ratio, the stiffness-to-weight ratio, excepptional dynamic strength, excellent insulating, superior durability in corrosive environments and better fatigue performance. It is an anisotropic matieral indeed as compared to conventional materials. The thickness of a PMC material can reach $0.3 \mathrm{~mm}$, so fiber orientations and stacking sequence of a PMC material can be adjusted to enhance structural behavior without any limitations given by existing structural configurations. The advanced composite material is an innovative and potential material, but its expansive price and its poor hysteretic performance make it unsuited for the web of shear panel dampers at present. Improving hysteretic behavior of advanced composite material maybe one of the most important and practical works.

\section{WEB BUCKLING}

An SPD usually experiences the following stages when subjected to shear loading: (1) the linear elastic stage, see Figure 5(a); (2) the yield occurrence, see Figure 5(b); (3) the inelastic buckling stage, see Figure 5(c); (4) the nonlinear elasto-plastic postbuckling stage, see Figures 5(d) and (e); and finally (5) the failure, see Figure 5(f). At the beginning of shear loading, shear stress is uniformly distributed across the web of an SPD. The web develops equal tensile and compressive stresses at $45^{\circ}$ and $135^{\circ}$ before buckling, and no out-of-plane deformation is observed. Next, few points reach the yield stress, and the remaining zones remain elastic. In the following process, the web becomes to show increasing elasto-plastic behavior. Once the web suddenly buckles at a certain load, it cannot carry any additional tensile and compressive load (the diagonal compressive stress remaining constant). Then a new load carrying mechanism is formed [23]. Shear stresses are no longer uniformly distributed and bending stresses develop due to local buckling. Large out-of-plane deflections occur and the sustained shear force increases. The SPD cannot carry further loads when yield points of the web form one or more complete narrow diagonal yield region [24]. The damper then fails to work.

In the above loading process, it is found that web buckling may sharply reduce shear strength of an SPD. Pinch phenomena may also be observed in the hysteresis curve. This not only weakens load bearing capacity of the shear panel damper but also leads it to unstable energy dissipation capacity. Hence web buckling should be avoided in the design, especially, in the early loading stage.

So far, great attempt has been made for this purpose. The research concerned covers the thickness of the web[12,15,24,25] and use of stiffeners[12,14,25,26]. Contributions of flanges to shear strength $[12,25]$ is also studied for further understanding mechanical behavior and web buckling of SPDs. The following discussions will be presented with regard to these three aspects. 
(a) initial elastic state

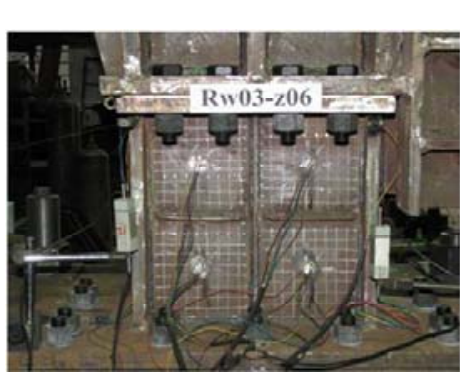

(b) yield occurrence and initial web buckling

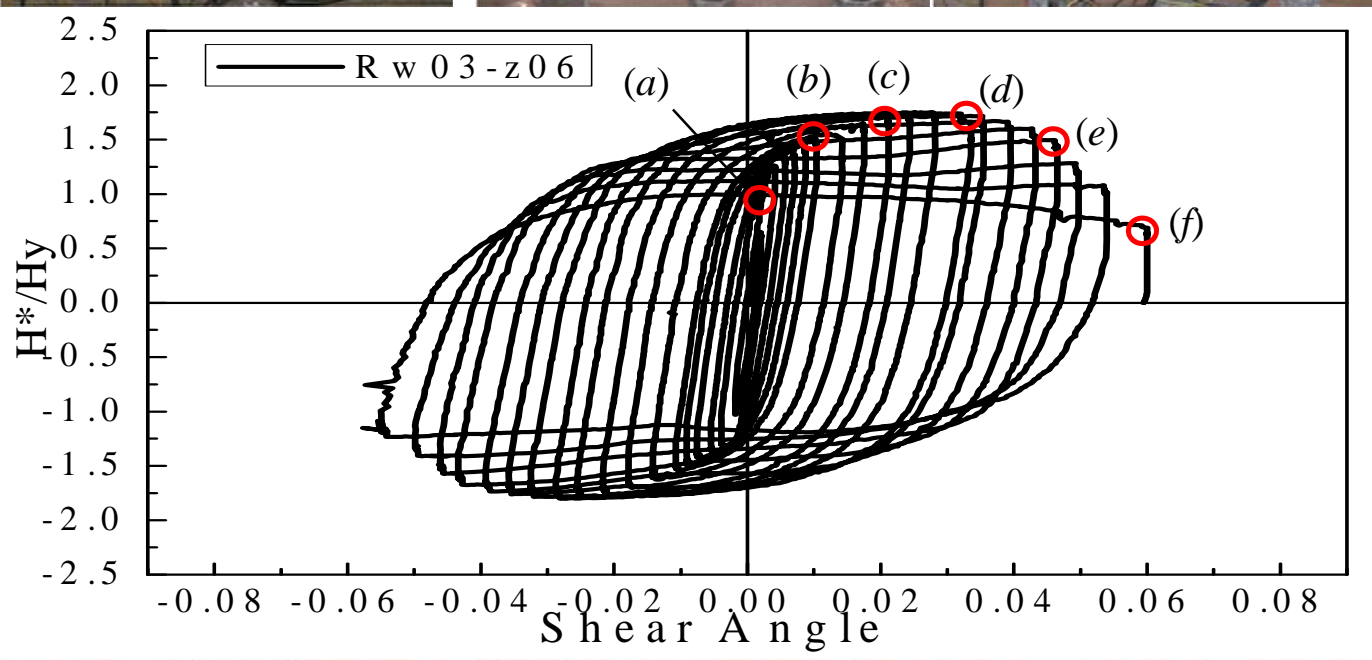

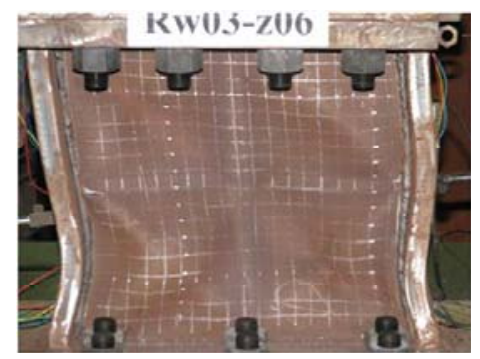

(d) tiny cracks

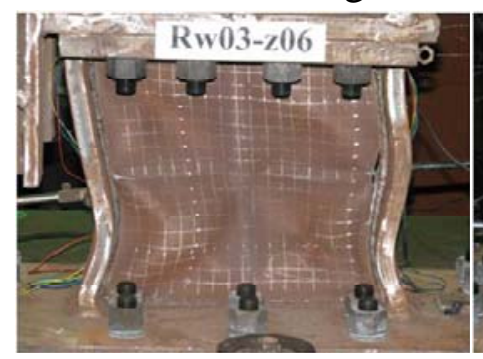

(e) cracks developing

(c) obvious web buckling

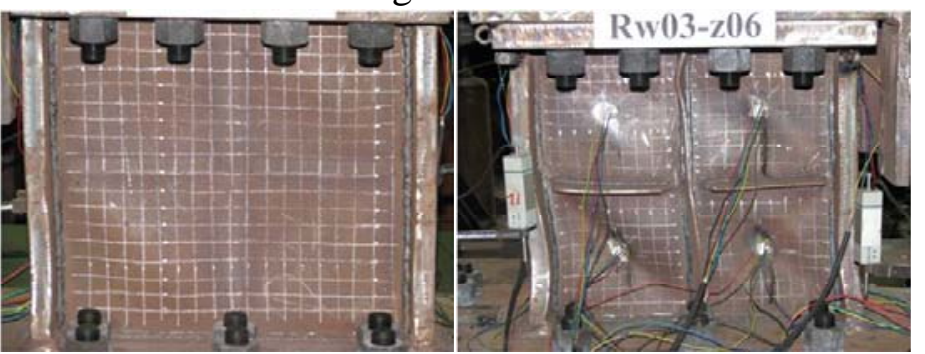


panel dampers. Numerical simulation results show that all the cases have good ductility up to 20 times of shear yield strain if the web slenderness parameter is less than 0.7. In this case, shear strength began deteriorating at 12 times of shear yield strain and hysteretic curve soon was terminated due to significant local buckling.

\subsection{Stiffener Effects}

Buckling phenomenon was often observed in unstiffened shear panel dampers during the early stage of shear loading. This may result in shear strength degradation, and may severely reduce energy dissipation capacity. It is commonly agreed that stiffeners can be effectively used to prevent local buckling during the early stage and avoid pinching and consequent strength degradation, especially for those with relative thin and slender webs.

Results of Chen et al. [12] demonstrated that if the stiffener rigidity, flange rigidity and web aspect ratio are in suggested range, their influence on the yield strength of an SPD are negligible. Then, the yield strength of an SPD is merely obtained from its cross section area. Namely, the merit of uses of stiffeners is to improve SPD ductility (large deformation capacity) while do not increase its strength.

Chen et al. [12] proposed an optimal stiffness ratio to control the number and rocky of stiffeners. Based on the experimental and numerical results, the optimal stiffness ratio of the stiffener was recommended as the value of 3 . In Reference [15], however, 10 was suggested. Clearly, there is a certain gap between two conclusions in determination the optimal value.

\subsection{Contribution of Flanges}

The main function of the flanges is to form fixed boundaries around the whole web. Then it may prevent rotation of web edges so as to increase the web buckling strength [15]. For simplicity, the flange thickness is always determined by several times of the web thickness in design. Generally the flange-to-web thickness ratio is taken as 4.0 in the previous works [3]. The numerical results of Chen et al. [12] also verified that the flanges are stiff enough as fixed web boundaries, given the ratio value of 4.0. It should be noted, however, that the contribution of flanges should be considered into the ultimate shear strength prediction. It is because that in large deformation state the frame action of the flanges also takes effect in addition to the web. The component resisted by flanges may reach as much as $13-20 \%$ of the total ultimate shear strength [12].

\section{HYSTERETIC BEHAVIOR AND RESTORING MODELS}

As energy dissipator, hysteretic behavior of SPDs influences directly seismic responses of a total structure during an earthquake. The seismic energy dissipated by SPDs is also the source of structural damping. Thus, correct understanding of hysteretic behavior and energy dissipating capacity as well as a corresponding restoring model of an SPD are thus an important prerequisite to accurately evaluate seismic responses of a structure with dampers.

\subsection{Hysteretic Behavior and Energy Dissipation}

Mainly due to the material and the web slenderness ratio, SPDs demonstrate different hysteretic behavior and energy dissipation capacity. Figure 6 shows three typical hysteretic curves of SPDs made by different metals $[3,12,19]$. As stated previously, large strain hardening is one remarkable feature of low yield point steel under reversal load. As can be seen from Figure 6(a), the shear force 
is increasing with increase of the SPD deformation. Study in Reference [3] has revealed that the significant strain hardening of the LYP 100 material was involved in the tested shear panels. This material feature resulted in the larger (about 1.5 times) cumulative dissipated energy than the equivalent linear-elastic and perfect-plastic system. However, under repeated equal displacement loading, the hysteretic curves trends to the second hysteretic curve, but the hardening does not occur at the same yield strength. This phenomenon is not the obvious isotropic hardening features either. Many models are developed to describe this special hardening rule, as will be discussed in the next subsection. Figure 6(b) clearly shows the typical kinematic hardening rule for an SPD made of mild steel. Numerical analysis results [12] indicated that for SPDs made of mild steel, the web is stockier, and the kinematical and isotropic effects are mixed together. If the web is medium stockier, the Buschinger effect is significant. For SPDs made of aluminum, its hysteretic curve shows remarkable pinch phenomenon, being similar to the flag shape as shown in Figure 6(c). Although the stable energy-dissipation capacity can be guaranteed through a certain construction details, the total energy dissipated is relatively smaller than that with a full hysteretic curve.

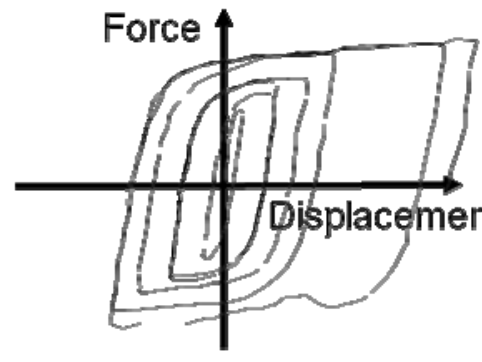

(a) low yield steel[3]

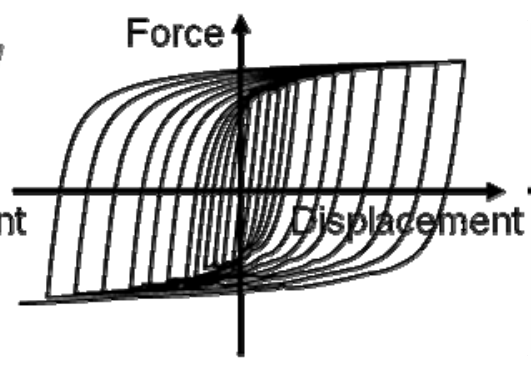

(b) mild steel[12]

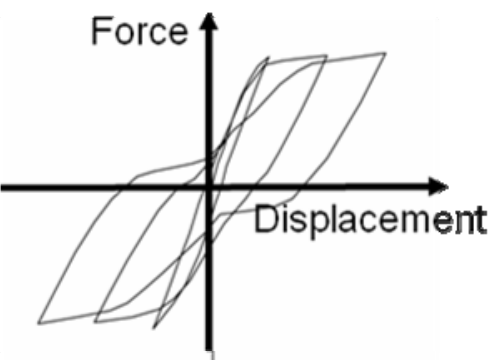

(c) aluminum[19]

Figure 6. Typical Force-displacement Curves of SPDs Made of Different Metal Materials

The web slenderness ratio is another factor which influences hysteretic behavior and energy dissipation capacity of an SPD. It is mainly resulted by the web local buckling. Test results obtained from LYP 100 and LYP 235 SPDs [13] showed that given the SPD made of the same steel material, the energy dissipated by both specimens are almost similar at medium deformation. However, in large deformation state, the increase of dissipating energy decreases for those with relative larger web slenderness ratio.

\subsection{Restoring Models}

The key issue in the numerical study on seismic reduction effect of an SPD is its accurate restoring model. Initially, in order to adopt the restoring model in the overall structure numerical analysis, an elastic-perfectly plastic model is often used due to simplicity. However, study on the ultimate shear strength of SPDs made of mild steel found that the damper has an overstrength which is about 1.1 to 1.6 times the yield strength of shear. This is mainly due to the steel strain hardening. And this feature is particularly evident in an SPD made of low yield point steel [27].

Considering the above feature, Takahashi and Shinabe [13] proposed four-fold-line-type restoring models. Chen et al. [12] proposed a simple bilinear model based on numerical test results, and gave the suitable range of the model. These two models are the simple models, although easy using, they cannot take into account the accurate prediction of strength and energy consumption. For example, due to the softening of steel, the equivalent linear method is often over-estimated the actual energy consumption of the damper during the plastic loading stage. The error can reach 15\% [12]. 
To correctly grasp the damper seismic control effect on the structure damage, the researchers dedicated to develop the restoring model which can accurately predict energy consumption. Kato-Akiyama model [28], as a representative model, divided the stress-strain curve into the skeleton curve, the unloading part and the stress softening part. Of these, the skeleton curve is obtained from the monotonic test. When the stress is not greater than the maximum value of historical stress, the stress-strain relationship is described by the unloading part, the stress softening part, and the stress from the uninstall section to the softening. Otherwise, it will move to the skeleton curve. Another Yamada-Tsuji model [29] is developed based on the Prager kinematic hardening model, combined by the isotropic hardening model and the kinematic hardening model, and then is modified to form a new IK model (ie, isotropic and kinematic model). But the IK model mainly describes hysteretic characteristics of the bilinear model. It is difficult to consider softening effect. To overcome this shortcoming, Nakashima et al. [30] introduced parameters from Ramberg-Osgood model into the IK model, and proposed so called IK RO model. The model not only has all the characteristics of IK model but also can simulate the gradual stiffness degradation behavior.

As can be seen, the above revised or improved restoring models are committed to accurately describe the force-displacement relationship of the dampers before its ultimate failure. But they do not take account of the degradation of strength and energy-dissipating capacity and even the failure of energy-dissipating devices, which result from the metal fatigue. Therefore, if such models are used in the nonlinear response analysis, once the damper deformation response is larger than the actual deformation that can bear, or the damper is damaged due to cumulative damage to a certain degree, then the analytical results will be real great error.

\section{APPLICATION IN CIVIL ENGINEERING}

SPDs described in this paper have already been applied successfully to many building and bridge structures. Two important buildings have been subjected to relatively large earthquakes and their performances have recorded. They are the Sylmar Hospital (in Los Angeles, California, shaken by the 1994 Northridge earthquake) and a 35-story building (in Kobe, Japan shaken by the 1995 Kobe earthquake) [2]. The Sylmar Hospital suffered severe damage to some non-structural elements and the 35-story building was found no visible damage.

The first application of SPDs in bridges is the San Francisco Oakland Bay Bridge east span. It is a $565 \mathrm{~m}$ long single tower steel self-anchored suspension bridge. The tower of the bridge consists of four steel shafts interconnected in the transverse and longitudinal directions by replaceable bolted steel shear panel dampers (they are called shear links in that case) [5]. The shafts were designed to remain elastic under the Safety Evaluation Earthquake (SEE) with a return period of 1,500 years while the SPDs were allowed to deform inelastically to protect the tower from permanent damage. Recently, another successful case is in Tempozan Bridge, Japan [31]. The SPD device is set at the junction (gasket) between the braces and the horizontal beam. The SPD is made of low yield point steel, to be yield plastically and absorb seismic energy to prevent braces from buckling and main girders from damage.

With the development of urban underground space and with the improvement of design and construction techniques, the modern underground structures trends to be of large span and complex structural style. In Shanghai, the most remarkable construction is the World Expo Axis underground complex engineering and Hongqiao integrated transport hub project. The former is $1045 \mathrm{~m}$ in length and $110.5 \mathrm{~m}$ in width. The largest span reaches $22 \mathrm{~m}$. The preliminary design of the width of the latter in the crowded region is not less than $24 \mathrm{~m}$. Their span is 3 times the span of conventional 
underground subway stations. The seismic safety of underground structures has received large attention of engineers and researchers. Due to its simplicity and efficiency, the SPD can be considered as a specific energy dissipation device in large underground structures. However it should be recognized that the seismic performance and damage mechanics of underground structures are different from the ground structures. Firstly, the underground structures are constrained by surrounding soils. As a result, dynamic effect is not so clearly if compared to the ground structures. Secondly, the axial compression ratio in underground structural columns is commonly large. Consequently SPDs will sustain high axial compression load. Further study about influence of high axial compression load on bearing capacity and energy dissipation capacity of SPD is then needed.

\section{CONCLUSIONS}

Due to feasibility and simplicity, research and application of shear panel dampers have become increasingly widespread. SPDs have been succeeded in controlling structural vibrations induced by earthquake ground motions in building and bridge structures. Now its efficiency in large span underground structures was verified and application in this field will become to truth in the soon coming future. At present, mechanical and hysteretic performance of SPDs and its seismic control effect in structures are being comprehensive and being in depth, making great achievements. This paper reviewed only two important issues, namely, web buckling and hysteretic behavior of SPDs. However, it can be seen that these studies have been done separately. Test data and parameters investigated were not unified for clear reference. For example, the web slenderness ratio, which is considered to be the most important parameter determining SPD mechanics and hysteretic performance, is defined by various forms. This leads to different values and optimal ranges that are recommended. The design method and control parameters of SPDs are not uniform, which is not beneficial to promote their application in practical engineering. Moreover, fatigue performance (especially at the conjunction region between the web, stiffeners and flanges) and large deformation behavior were found to be a subject that was worth further study for shear panel dampers to be used in structures.

\section{ACKNOWLEDGMENTS}

This research was supported by the National Natural Science Foundation of China (Grant No. 50908169), National Basic Research Program of China (973 Program: 2011CB013600), State Key Laboratory of Geo-Hazard Prevention and Geo-Environment Protection (Grant No. SKLGP2011K009), Program for Changjiang Scholars and Innovative Research Team in University (PCSIRT, IRT1029), the Fundamental Research Funds for the Central Universities and the Kwang-Hua Fund for College of Civil Engineering, Tongji University. All supports are gratefully acknowledged.

\section{REFERENCES}

[1] Housner, G.W., Bergman, L.A., Caughey, T.K., Chassiakos, A.G., Claus, R.O., Masri, S.F., Skelton, R.E., Soong, T.T., Spencer, B.F. and Yao, J.T.P., "Structural Control: Past, Present, and Future”, J. Eng. Mech., ASCE, 1997, Vol. 123, No. 9, pp. 897-971.

[2] Japanese Society of Steel Construction, "Seismic Response Behavior and Design Method for Frame Structures with Hysteretic Dampers”, Tokyo: Japanese Society of Steel Construction, 1998. (in Japanese) 
[3] Nakashima, M., Iwai, S., Iwata, M., Takeuchi, T., Konomi, S., Akazawa, T. and Saburi, K., "Energy Dissipation Behavior of Shear Panels Made of Low Yield Steel”, Earthquake Engineering \& Structural Dynamics, 1994, Vol. 23, No. 12, pp. 1299-1313.

[4] Tanaka, K. and Sasaki, Y., "Hysteretic Performance of Shear Panel Dampers of Ultra Low-yield-strength Steel for Seismic Response Control of Buildings”, 12WCEE (CD-Rom), Auckland, NZ, 2000.

[5] McDaniel, C.C., Uang, C.M. and Seible, F., "Cyclic Testing of Built-up Steel Shear Links for the New Bay Bridge”, J. Struct. Eng., ASCE, 2003, Vol. 129, No. 6, pp. 801-809.

[6] Abolhassan, A.A., "Seismic Behavior and Design of Steel Shear Walls", the 2001 SEOANC Seminar, Structural Engineers Assoc. of Northern California, November 7, 2001.

[7] Bergman, D.M. and Goel S.C., "Evaluation of Cyclic Testing of Steel-plate Devices for Added Damping and Stiffness”, Report No. UMCE87-10. Univ. of Michigan, Ann Arbor, 1987.

[8] Tsai, K., Chen, H.W., Hong, C.P. and Su Y.F., “Design of Steel Triangular Plate Energy Absorbers for Seismic-resistant Construction”, Earthquake Spectra, 1993, Vol. 9, No. 3, pp. 505-528.

[9] De la Llera, J.C., Esguerra, C. and Almazan, J.L., "Earthquake Behavior of Structures with Copper Energy Dissipators”, Earthquake Engineering \& Structural Dynamics, 2004, Vol. 33, No. 3, pp. 329-358.

[10] Chan, R.W.K. and Albermani, F., "Experimental Study of Steel Slit Damper for Passive Energy Dissipation”, Eng. Struct., 2008, Vol. 30, No. 4, pp. 1058-1066.

[11] Clark, P., Aiken, I., Ko, E., Kasai, K. and Kimura, I., "Design Procedures for Buildings Incorporating Hysteretic Damping Devices”, Proceedings of 1999 Annual Convention of the Structural Engineers Association of California, Santa Barbara, California, 1999.

[12] Chen, Z.Y., Ge, H.B. and Usami, T., "Hysteretic Model of Stiffened Shear Panel Dampers", Journal of Structural Engineering, 2006, Vol. 132, No. 3, pp. 478-483.

[13] Takahashi, Y. and Shinabe, Y., "Experimental Study on Restoring Force Characteristics of Shear Yielding Thin Steel Plate Elements”, J. Struct. Constr. Eng., AIJ, 1997, Vol. 494, pp. 107-114

[14] Alinia, M.M. and Dastfan, M., "Cyclic Behavior, Deformability and Rigidity of Stiffened Steel Shear Panels”, Journal of Constructional Steel Research, 2007, Vol. 63, No. 4, pp. 554-563.

[15] Chan, R.W.K., Albermani, F. and William, M.S., "Evaluation of Yielding Shear Panel Device for Passive Energy Dissipation”, Journal of Constructional Steel Research, 2009, Vol. 65, No. 2, pp. 260-268.

[16] Aref, A.J. and Jung, W.Y., “Advanced Composite Panels for Seismic and Vibration Mitigation of Existing Structures”, Journal of Engineering Materials and Technology, 2006, Vol. 28, No. 4, pp. 618-632.

[17] Mallela, U.K. and Upadhyay, A., "Buckling of Laminated Composite Stiffened Panels Subjected to In-plane Shear: A Parametric Study”, Thin-Walled Structures, 2006, Vol. 44, No. 3, pp. 354-361.

[18] Nippon Steel Corporation, http://www.nsc.co.jp/product/plate/pdf/ac120.pdf, Accessed 19 December 2011.

[19] De Matteis, G., Mazzolani, F.M. and Panico, S., "Experimental Tests on Pure Aluminium Shear Panels with Welded Stiffeners”, Engineering Structures, 2008, Vol. 30, No. 6, pp. 1734-1744.

[20] De Matteis, G., Mazzolani, F.M. and Panico, S., "Pure Aluminium Shear Panels as Dissipative Devices in Moment-resisting Steel Frames”, Earthquake Engineering \& Structural Dynamics, 2007, Vol. 36, No. 7, pp. 841-859.

[21] Rai, D.C., "Inelastic Cyclic Buckling of Aluminum Shear Panels”, Journal of Engineering Mechanics, 2002, Vol. 128, No. 11, pp. 1233-1237. 
[22] Hull, D. and Clyne, T.W., “An Introduction to Composite Materials”, Cambridge University Press, 1996.

[23] Porter, D.M., Rockey, K.C. and Evans, H.R., "The Collapse Behavior of Plate Girders Loaded in Shear”, The Struct. Eng., 1975, Vol. 53, No. 8, pp. 313-325.

[24] Alinia, M.M., Habashi, H.R. and Khorram, A., "Nonlinearity in the Postbuckling Behaviour of Thin Steel Shear Panels”, Thin-Walled Structures, 2009, Vol. 47, No. 4, pp. 412-420.

[25] Jain, S., Rai, D.C. and Sahoo, D.R., "Postyield Cyclic Buckling Criteria for Aluminum Shear Panels”, Journal of Applied Mechanics, 2008, Vol. 75, No. 2, Paper No. 021015.

[26] Ambur, D.R., Jaunky, N. and Hilburger, M.W., "Progressive Failure Studies of Stiffened Panels Subjected to Shear Loading”, Composite Structures, 2004, Vol. 65, No. 2, pp. 129-142.

[27] Nakashima, M., "Strain-hardening Behavior of Shear Panels Made of Low-yield Steel. 1: Test”, Journal of Structural Engineering, 1995, Vol. 121, No. 12, pp. 1742-1749.

[28] Kato, M. and Akiyama, H. "Experimental Principal of Stress-strain Hysteretic Curves for Steel Materials”, Summaries of Technical Papers of Annual Meeting, AIJ, 1973, pp. 937-938.

[29] Yamada, M. and Tsuji, B., "Stress-strain Behavior of Structural Steels. I: Combined Isotropic and Kinematic Hardening Model”, Proc. Annu. Meeting of the Arch. Inst. of Japan, Tokyo, Japan, 1965, pp. 1447-1450.

[30] Nakashima, M., Akazawa, T. and Tsuji, B., "Strain-hardening Behavior of Shear Panels Made of Low-yield Steel. 2: Model”, Journal of Structural Engineering, 1995, Vol. 121, No. 12, pp. 1750-1757.

[31] Nishioka, T., "Seismic Control Techniques for Large-span Bridges, in the Case of Hanshin Expressway”, Journal of Steel Structures \& Construction, 2009, Vol. 72, pp. 7-10. 